\section{Respiratory Physiology}

\section{P247 SPECIFICITY OF DYSPNOEA RELIEF WITH INHALED FUROSEMIDE}

JC Grogono, C Butler, H Izadi, SH Moosavi. Oxford Brookes University, Oxford, UK

\subsection{6/thoraxjnl-2016-209333.390}

Introduction Dyspnoea is prevalent and reduces quality of life in patients with chronic disease. Inhaled furosemide offers a potential complementary novel treatment for these patients. The mechanism of action is unclear but current theory suggests sensitisation of slowly adapting pulmonary stretch receptors (saPSR) altering neural feedback that informs the brain of the level of breathing. Clinical dyspnoea comprises several components including air hunger $(\mathrm{AH}$; an uncomfortable urge to breathe) and a sense of breathing work/effort (WE) which are thought to arise from different neural pathways. We therefore hypothesised that inhaled furosemide would relieve $\mathrm{AH}$ but not WE.

Methods A double-blind, placebo-controlled trial was conducted on healthy volunteers ( $\mathrm{n}=16 ; 9$ males). Test sessions involved 3 inhalations of furosemide $(40 \mathrm{mg})$ or saline $(4 \mathrm{ml})$ separated by 30-60 mins. Order of inhalations was furosemide-saline-furosemide in half the subjects and saline-furosemide-saline in the other half. Before and after each inhalation, $\mathrm{AH}$ was induced with hypercapnia (mean \pm SD PCO2 $=49.8 \pm 3.7 \mathrm{mmHg}$ ) and constrained ventilation (mean \pm SD $9.2 \pm 1.5 \mathrm{l} / \mathrm{min}$ ) on one test-day while WE was induced with targeted ventilation (mean \pm SD $16.6 \pm 3.1 \mathrm{l} / \mathrm{min})$ and external resistive load $(20 \mathrm{cmH} 2 \mathrm{O} / \mathrm{L} / \mathrm{s})$ on the other test-day. During saline inhalations $1.5 \mathrm{mg}$ furosemide in $15 \mathrm{ml}$ saline was infused to match the expected systemic absorption of furosemide from the lungs over 15 mins of inhalation. Corresponding infusions of saline during furosemide inhalations maintained blinding from noticeable diuresis. Subjects rated $\mathrm{AH}$ or WE every 20s on a visual analogue scale (VAS). Hypercapnia $(\mathrm{AH})$ or targeted ventilation (WE) were imposed for 4 mins and the ratings in the last minute were analysed using Linear Mixed Model procedure (SAS 9.4).

Results The final model produced a main effect of mist (furosemide or saline; $\mathrm{p}=0.016$ ), time (pre or post inhalation;

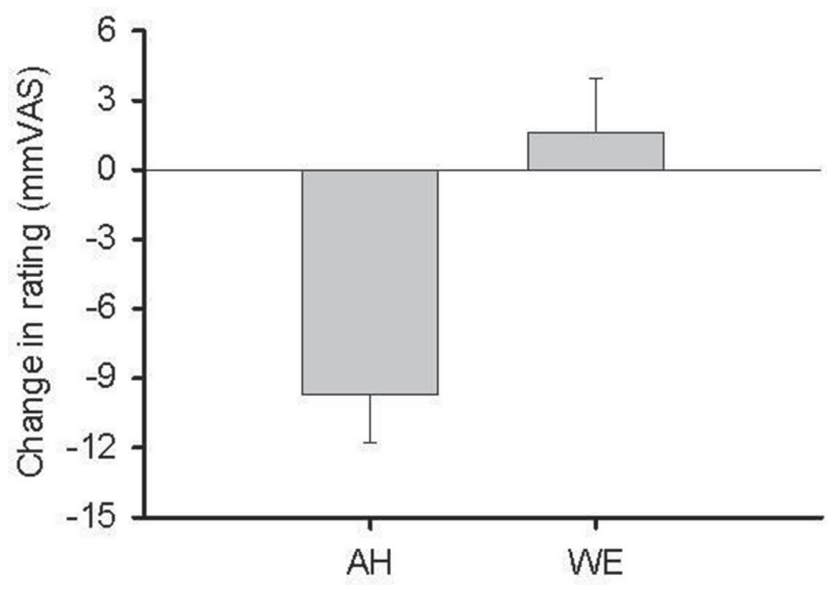

Abstract P247 Figure 1 Mean \pm SE changes in VAS ratings before and after inhaled furosemide relative to the change before and after inhaled saline for experimentally induced air hunger (AH) and experimentally induced breathing work/effort (WE) in 16 healty individuals. $\mathrm{p}=0.047)$ and a significant condition (AH or WE)*mist interaction $(\mathrm{p}=0.004)$. Mean \pm SE AH was significantly lowered by inhaled furosemide relative to inhaled saline $(-9.7 \pm 2.1 \mathrm{~mm}$ VAS; $\mathrm{p}=0.0015)$ but mean $\pm \mathrm{SE}$ WE was not $(+1.6$ $\mathrm{mm} \pm 2.4 ; \mathrm{p}=0.903)$.

Conclusion Inhaled Furosemide is effective at relieving $\mathrm{AH}$, but not WE. This is consistent with a mechanism involving modulation of parenchymal lung mechanoreceptor activity leading to dyspnoea relief that specifically applies to the $\mathrm{AH}$ component. The treatment may therefore benefit patients with the most unpleasant form of dyspnoea.

\section{P248 PATIENT ELIGIBILITY FOR ANTI-FIBROTIC THERAPY IN IDIOPATHIC PULMONARY FIBROSIS CAN BE ALTERED BY USE OF DIFFERENT SETS OF REFERENCE VALUES FOR CALCULATION OF FVC PERCENT PREDICTED}

K Ward, L Spurr, NR Goldman, GA Margaritopoulos, M Kokosi, E Renzoni, F Chua, TM Maher, S Ward, AU Wells. Interstitial Lung Disease Unit, Department of Respiratory Medicine, Royal Brompton Hospital, London, UK

\subsection{6/thoraxjnl-2016-209333.391}

Introduction Antifibrotic drugs for idiopathic pulmonary fibrosis (IPF) patients in England and Scotland are only available to those with FVC percent predicted (FVC\%pred) less than or equal to $80 \%$. The prescribing guidance does not state which reference values should be used.

\section{Aims}

To find out if the use of different sets of reference values affects the numbers of patients with FVC\%pred greater than and less than $80 \%$.

To find out which reference equations were in use at UK centres prescribing antifibrotics for IPF in April 2016.

Methods We searched databases for patients diagnosed with IPF at our interstitial lung disease (ILD) unit from $1 / 1 / 2010$ to $31 / 12$ / 2015. We calculated FVC\%pred using three different sets of reference values (ECSC, GLI or NHANES). The chief respiratory physiologist in each ILD centre in England was contacted and asked which reference values they used to calculate FVC\%pred. In Scotland, four hospitals with an ILD MDT were contacted and asked the same. McNemar tests were used to compare the proportion of patients eligible for antifibrotic prescription when FVC\%pred was calculated by ECSC or either NHANES or GLI.

Results See Table 1. We identified 671 unique patients: after exclusions, 528 had complete data.

There was a higher proportion of patients calculated to have an $\mathrm{FVC} \%$ pred $>80 \%$ (ineligible for antifibrotics) using ECSC than GLI: Chi-square 22.0, $1 \mathrm{df}, \mathrm{P}<0.0001$. The difference in proportions was greater when ECSC was compared to NHANES: Chi square 33.03, $1 \mathrm{df}, \mathrm{P}<0.0001$. Of 30 patients with ECSC FVC\%pred 80-85\%, 27 [90\%: 95\% CI: 79-100\%) had their FVC\%pred fall to $<80 \%$ when recalculated with NHANES.

18 of 20 ILD centres in England were using ECSC to calculate FVC\%pred; others used GLI $(n=1)$ and Falaschetti $(n=1)$. All four Scottish centres were using ECSC.

Discussion Many patients with ECSC FVC\%pred too high for antifibrotics fall into the eligible range when NHANES, the set of reference values used in the ASCEND pirfenidone trial, or GLI, as recommended by the UK Association for Respiratory Technology and Physiology(ARTP) are used.

Conclusions We urge physicians and physiologists to ensure that reference values used to calculate FVC\%pred are cited in lung 
Abstract P248 Table 1 Results for all IPF patients: Demographics and Disease Severity by FVC percent predicted

\begin{tabular}{|c|c|c|c|c|c|}
\hline \multicolumn{6}{|l|}{ Total IPF patients $n=528$} \\
\hline \multicolumn{3}{|l|}{ Sex } & Male & Female & Row total \\
\hline \multicolumn{3}{|l|}{ Number of patients (proportion) } & $431(82 \%)$ & $97(18 \%)$ & 528 \\
\hline \multicolumn{3}{|l|}{ Ethnicity } & Caucasian & \multicolumn{2}{|l|}{ Non-Caucasian } \\
\hline \multicolumn{3}{|l|}{ Number of patients (proportion) } & $453(86 \%)$ & $75(14 \%)$ & 528 \\
\hline & Characteristic & Unit & Median & \multicolumn{2}{|l|}{ IQ range } \\
\hline & Age & years & 72 & \multicolumn{2}{|l|}{$68-78$} \\
\hline & FVC & litres & 2.175 & \multicolumn{2}{|l|}{$1.700-2.780$} \\
\hline \multirow[t]{5}{*}{ Reference equations used } & ECSC & FVC\%pred & 64.9 & \multicolumn{2}{|l|}{$52.2-75.9$} \\
\hline & GLI & FVC\%pred & 60.6 & \multicolumn{2}{|l|}{$49.3-72.4$} \\
\hline & NHANES & FVC\%pred & 58.9 & \multicolumn{2}{|l|}{$49.4-70.0$} \\
\hline & & & \multicolumn{3}{|c|}{ FVC percent predicted range } \\
\hline & & & $>80 \%$ & $<80 \%$ & Row total \\
\hline \multirow[t]{3}{*}{ Reference equations used } & ECSC & Number of patients & 98 & 430 & 528 \\
\hline & GLI & & 73 & 455 & 528 \\
\hline & NHANES & & 64 & 464 & 528 \\
\hline
\end{tabular}

percent predicted; $\mathrm{IQ}=$ interquartile

function reports. Those choosing reference values must be aware of implications for patients.

\section{P249 COMPARISON OF PHYSIOLOGICAL VERSUS MATHEMATICAL METHODS FOR QUALITY CONTROL IN MBW NORMALISED PHASE III ANALYSIS}

${ }^{1} \mathrm{M}$ Arigliani, ${ }^{2} \mathrm{~N}$ Verger, ${ }^{3} \mathrm{E}$ Raywood, ${ }^{3} \mathrm{~J}$ Duncan, ${ }^{4} \mathrm{~A}$ Bush, ${ }^{5} \mathrm{P}$ Aurora on behalf of the London Cystic Fibrosis Collaboration. 'Department of Clinical and Experimental Medical Sciences, Unit of Paediatrics, University Hospital of Udine, Udine, Italy; ${ }^{2}$ Université Pierre et Marie Curie, Paris, France; ${ }^{3}$ Respiratory, Critical Care and Anaesthesia Section, IIIP, UCL Institute of Child Health, London, UK; ${ }^{4}$ The National Heart and Lung Institute, Imperial College, London, UK; ${ }^{5}$ Department of Respiratory Medicine, Great Ormond Street Hospital for Children, London, UK

\subsection{6/thoraxjnl-2016-209333.392}

Background Breathing pattern cannot be controlled in small children, so multiple breath washout SnIII analysis has to exclude inadequate volume breaths.

Aim To compare an existing mathematical breath exclusion algorithm with a physiological method.

Methods School age children with CF (30) and controls (30) performed SF6MBW with mass spectrometer, with uncontrolled tidal breathing. Two different breath exclusion methods were compared, with exclusion based on:

1) Expired tidal volume (VT) deviating by $>25 \%$ of the median $\mathrm{VT}^{1}$

2) VT $<3$ Langley dead space ${ }^{2}$ volume or $90 \%$ bigger than the median VT

Runs with $>33 \%$ excluded breaths were removed. Volume corrected Scond was calculated from subjects with 3 valid runs.

Results Far fewer subjects were excluded by the physiological Langley method, than by the mathematical method (Table). The mean and SD for Scond was identical by both methods, implying that the mathematical algorithm excludes valid data.

Abstrct P249 Table 1
\begin{tabular}{|l|c|c|c|}
\hline & Breath size exclusion criteria & \multirow{2}{*}{ Mean diff $(95 \% \mathrm{Cl})$} \\
\hline & $\mathrm{VT} \pm 25 \%$ & $\begin{array}{c}\text { Langley } \\
\text { correction }\end{array}$ & \\
\hline Number of subjects excluded & $30 / 60$ & $12 / 60$ & \\
\hline $\mathrm{S}_{\text {cond }}(\mathrm{SD})$ controls & $0.009(0.012)$ & $0.011(0.012)$ & $-0.011 ; 0.006$ \\
\hline $\mathrm{S}_{\text {cond }}(\mathrm{SD}) \mathrm{CF}$ & $0.070(0.025)$ & $0.072(0.025)$ & $-0.004 ; 0.0009$ \\
\hline
\end{tabular}

Conclusion A physiological approach to data cleaning prior to SnIII analysis allows retention of data that would be inappropriately excluded mathematically.

\section{REFERENCES}

1 Bigler A, et al. Paediatric Pulmonol 2015;50(8):805-13.

2 Langley FE, et al. Colloques INSERM 1975;51:209-212.

\section{P250 REAL FLIGHT SPO2 COMPARES WITH HYPOXIC CHALLENGE TESTING IN ADULTS WITH CYSTIC FIBROSIS}

R Peat, J Furlong, E Spencer, D Russell, M Ledson, MJ Walshaw. Liverpool Heart and Chest Hospital, Liverpool, UK

\subsection{6/thoraxjnl-2016-209333.393}

Introduction Limited data are available comparing air travel with the hypoxic challenge test (HCT) in adults with cystic fibrosis (CF). The aim of this study was to assess the predictive capability the HCT to in-flight hypoxaemia in adult passengers with CF.

Methods Fifteen subjects (three male) volunteered for this study. Lung function measurements (FEV1) were performed pre and post flight. Oxygen saturation measured by pulse oximetry (SpO2) and symptoms were recorded in-flight on both outward and inward flights. The HCT was performed post flight and the in-flight oxygenation response was compared to the HCT and lung function results. 